\title{
TITLE:
}

\section{The norm-dependent effect of watching eyes on donation}

$\operatorname{AUTHOR}(\mathrm{S}):$

Kawamura, Yuta; Kusumi, Takashi

\section{CITATION:}

Kawamura, Yuta ...[et al]. The norm-dependent effect of watching eyes on donation. Evolution and Human Behavior 2017, 38(5): 659-666

ISSUE DATE:

2017-09

URL:

http://hdl.handle.net/2433/228285

\section{RIGHT:}

(c) 2017. This manuscript version is made available under the CC-BY-NC-ND 4.0 license

http://creativecommons.org/licenses/by-nc-nd/4.0/; The full-text file will be made open to the public on 01 September 2018 in accordance with publisher's 'Terms and Conditions for Self-Archiving'.; この論文は出版社版でありません。引 用の際には出版社版をご確認ご利用ください。; This is not the published version. Please cite only the published version. 
Evolution and Human Behavior, vol. 38, No. 5, 659-666, 2017

DOI: 10.1016/j.evolhumbehav.2017.05.003

The norm-dependent effect of watching eyes on donation

(author version)

Yuta Kawamura $^{1,2}$, Takashi Kusumi ${ }^{1}$

${ }^{1}$ Graduate School of Education, Kyoto University, Japan.

${ }^{2}$ Japan Society for the Promotion of Science, Tokyo, Japan

Correspondence should be addressed to:

Yuta Kawamura

Department of Education, Kyoto University

Yoshida-honmachi, Sakyo-ku, Kyoto 606-8501, Japan.

E-mail address: kawamura.yuta.83c@st.kyoto-u.ac.jp 


\section{Abstract:}

Although many previous studies have shown that eye-like images promote generosity, the mechanism of this "watching eyes effect" remains unclear. One possible cause is the concern for a good reputation as a generous person, while the other is the concerns for a bad reputation as a norm violator. To elucidate which of these two concerns is the main influencer, the present study conducted a laboratory experiment that investigated whether the watching eyes effect changed depending on social norms. If the concern for a good reputation leads to the effect, prosocial behavior would be more likely in the presence of watching eyes, regardless of the social norms involved. However, if the concern for avoiding a bad reputation as a norm violator leads to the effect, watching eyes promote prosocial behavior only in the existence of prosocial norms. In the original study, participants were asked to make a donation under conditions in which eye-like images either were or were not present. In addition to the eye-like images, we manipulated prosocial norms by informing each participant of either high or low mean donation amounts given by previous participants. We found that watching eyes promoted donations only when a prosocial norm existed. This supports the idea that the watching eyes effect is caused by a concern for avoiding a bad reputation from violating norms. However, in a replication study, we were unable to replicate the original results; watching eyes did not promote generosity regardless of the norm. Taken together, we discussed the moderation effect of norms and the possibility of other moderators.

Keywords:

Reputation; Prosocial behavior; Eye-like images; Norm; Watching eyes effect; Charitable giving 


\section{Introduction}

Previous studies have repeatedly examined whether individuals become generous when they are "watched" by eye-like images (e.g., Haley and Fessler, 2005; Nettle et al., 2013; Sparks and Barclay, 2013). For example, Haley and Fessler (2005) demonstrated that participants who were shown eye-like images distributed more of their money to strangers than did participants who were not shown the images. In addition, Ernest-Jones, Nettle, and Bateson (2011) found that when the experimenter put a poster of eyes in a real-world cafeteria situation, littering decreased. Such a "watching eyes effect" has been observed in both laboratory settings (Haley and Fessler, 2005; Nettle et al., 2013; Rigdon, Ishii, Watabe, and Kitayama, 2009; Sparks and Barclay, 2013) and out in the field (Bateson, Nettle, and Roberts, 2006; Ernest-Jones et al., 2011; Powell, Roberts, and Nettle, 2012).

While many studies have found the watching eyes effect, some studies did not replicate the effect (e.g., Matsugasaki, Tsukamoto, and Ohtsubo, 2015; Raihani and Bshary, 2012; Tane and Takezawa, 2011). Further, recently Northover, Pedersen, Cohen, and Andrews (2017) conducted meta analyses about the watching eyes effect and reported that watching eyes did not promote generosity across a wide range of situations. One plausible reason the results are mixed is that there are other factors that moderate the effect. Therefore, it is important to consider when and why the watching eyes promote generosity.

Why do eye-like images promote generosity? Concerning one possibility, researchers have argued that because pictorial eyes activate reputational concern, they promote prosocial behavior (e.g., Haley and Fessler, 2005). It is known that we are likely to choose a partner with whom to interact and cooperate, based on that individual's reputation (e.g., Sylwester and Roberts, 2013). Consequently, a person with a good reputation receives social benefits, whereas a person with a bad reputation receives negative sanctions such as punishment or ostracism. Therefore, it is important to maintain one's reputations of being a generous person. More importantly, some researchers have considered that people are so sensitive to reputation that not only real observers, but also eye-like images - in other words, subtle perception cues of "others" - can activate reputational concerns. Komiya, Oishi, and Lee (2016) conducted a cognitive experiment in which participants classified a string of letters into words or non-words as accurately and quickly as possible. The results showed that the participants reacted faster to reputational words (e.g., reputation, outcast, and rumor) in a condition consisting of eyes 
being presented during the task than in one in which there were no eyes present. These findings suggest that people activate concerns about their reputations when they are being "watched" by mere pictorial representations of eyes.

Reputational concern can be divided into two components: seeking a good reputation and avoiding a bad one. Which concern is more important in inducing the watching eyes effect? On the one hand, a body of research argues that the concern for a good reputation leads to prosocial behaviors, because people with good reputations would receive social benefits, such as good interaction partners in the future (e.g., Barclay and Willer, 2007). In support of this idea, some studies have shown that the expectation of social rewards, rather than the avoidance of punishment, promoted prosocial behavior in the presence of pictorial eyes (Oda, Niwa, Honma, and Hiraishi, 2011; Powell et al., 2012). Indeed, Oda et al. (2011) asked their participants to answer a post-task questionnaire concerning their thoughts during a money distribution task. They found that the watching eyes effect was mediated by expectations of future rewards; that is, individuals expected future rewards in the presence of watching eyes, and they were more likely than those who were not presented with eyes to behave in a prosocial manner. We refer to this explanation as the seeking a good reputation hypothesis.

On the other hand, people sometimes behave generously to avoid a bad reputation and the threat of future punishment (e.g., Masclet, Noussair, Tucker, and Villeval, 2003). In a situation in which generosity is normative, those who do not behave in a prosocial manner are judged as "atypical people" who violate social norms. Consequently, they get a bad reputation and become the target of negative sanctions such as punishment or ostracism (e.g., Chudek and Henrich, 2011). Some studies have argued that the concern for avoiding a bad reputation is responsible for the watching eyes effect. Nettle et al. (2013) showed that money distribution variance becomes smaller (i.e., there are fewer extremely high or low outlying values) in front of eyes. This suggests that participants conform to local norms to avoid a bad reputation, rather than becoming equally generous. Some additional findings fit the avoiding a bad reputation hypothesis (e.g., Bateson et al., 2006; Ernest-Jones et al., 2011; Oda, Kato, and Hiraishi, 2015). For example, Bateson et al. (2006) put pictorial eyes on an honesty box in an office, and found that in front of eyes people were more likely to pay for their drinks. If others saw that they did not pay for their drinks, they would be thought of as people who did not follow local rules and would be charged accordingly. Therefore, this paying for their drinks when eyes were present could be interpreted as behavior aimed at avoiding a bad reputation. 
To test these two alternative hypotheses, the present study focused on social norms of generosity. In a situation in which prosocial behavior is not the social norm, not being generous is no longer non-normative; that is, a non-generous person would not be seen as a norm violator. Then, from the perspective of avoiding a bad reputation for norm violation, an individual would not behave generously, even when there are eyes watching. On the other hand, from the perspective of gaining a good reputation for prosocial behavior, acting in a prosocial manner always leads to a good reputation; thus, being watched by eyes would induce prosocial behaviors regardless of the presence of prosocial norms.

Two studies have already examined whether manipulating the norms of generosity influences the watching eyes effect (Bateson, Callow, Holmes, Redmond Roche, and Nettle, 2013; Fathi, Bateson, and Nettle, 2014). For example, Bateson et al. (2013) investigated whether littering decreased in the presence of watching eyes, or according to the amount of litter present on the ground. If the watching eyes effect is caused by the concern for avoiding a bad reputation, eyes would inhibit littering only when the ground was clean. The results showed, however, that regardless of the litter on the ground, eyes decreased littering behavior. Thus, their results provide support for the seeking a good reputation hypothesis.

Although it is important to investigate these effects in real-world settings, many other factors, such as the level of anonymity, could have confounded with Bateson et al.'s (2013) manipulations. To eliminate these confounding factors, Fathi et al. (2014) conducted a donation experiment manipulating norms and eyes in a laboratory setting. They brought participants to a cubicle featuring a poster with or without eyes. At the end of the experiment, they asked the participants whether they would donate something to a local organization by putting a charity collection jar on the desk. As a manipulation of a prosocial norm, they manipulated the amount of money the participants could see in the charity jar. The majority of the coins in the jar were worth 1 or $2 £$ in the large-norm condition and 10 or 20 pence in the small-norm condition. Their results found a main effect of eyes, thus supporting the seeking a good reputation hypothesis.

Although these studies are well-designed experiments, we should note one common limitation: it is likely their norm manipulation was weak. Although Bateson et al. (2013) manipulated the norm about littering, the norm of no-littering is generally 
shared; it is likely that their manipulation of norm was not strong enough to override the existing norm. In relation to Fathi et al. (2014), the per capita donation amount could not be determined. Although the types of coins in the jar somewhat reflected whether others donated more or less, the normative behavior was unclear. Indeed, in reference to donation amount, there was no difference between the large-norm and small-norm conditions. Therefore, it is crucial to re-examine whether the watching eyes effect on generosity is dependent upon social norms by manipulating norms in such a way that participants can clearly understand what is normative.

In the present study, we examined whether the watching eyes effect depends on social norms. Unlike Fathi et al.'s (2014) study, we directly presented the mean amount of others' donations to clarify the social norm. Considering the fact that previous studies also presented the mean amount of others' donations as norm information (Nook, Ong, Morelli, Mitchell, and Zaki, 2016; Shang and Croson, 2009), it is reasonable to use the mean amount of others' donations as norm information. By manipulating the eyes and norms, we examined the seeking good reputation and avoiding bad reputation hypotheses as both null and alternative hypotheses. We considered that if the watching eyes effect is caused by the concern for a good reputation, the watching eyes would promote donations regardless of the social norms. On the other hand, if the watching eyes effect is caused by the concern for avoiding a bad reputation, watching eyes would promote donations only in the presence of a prosocial norm.

\section{Original Study}

\subsection{Methods}

\subsubsection{Participants and design}

One hundred thirty-nine Japanese university students aged 18-32 years ( $M=20.8$, $S D=1.96$; 80 males and 59 females) were paid 1000 JPY to participate (120 JPY = approximately 1 USD). They were randomly allocated to one condition of a 2 (eyes: eyes vs. no eyes) $\times 2$ (norm: prosocial vs. non-prosocial) between-participants design: (a) prosocial norm with eyes $(n=35)$, (b) prosocial norm without eyes $(n=35)$, (c) nonprosocial norm with eyes $(n=35)$, and $(d)$ non-prosocial norm without eyes $(n=34)$. The participant sex ratio was almost equal throughout all conditions. This study was approved by the ethics committee at the Graduate School of Education of Kyoto University, and consent was obtained from all the participants before the experiment was conducted.

\subsubsection{Procedure}


Under the cover story that the experiment was conducted to investigate individual differences in cognitive activity, university students participated in the experiment. Before they arrived at the laboratory, the participants completed an online survey that included demographic questions and some questionnaires. Participants answered the Praise Seeking and Rejection Avoidance Questionnaire (Kojima, Ohta, and Sugawara, 2003), the Japanese version of the Social Phobia Scale (Kanai et al., 2004) and the Japanese version of the Ten Item Personality Inventory (Oshio, Abe, and Cutrone, 2012), the Animism Scale for Adults (Ikeuchi, 2010). Because we administered these questionnaires for exploratory purposes, we do not discuss them further. At the end of the survey, they were randomly assigned an identification number. Upon their arrival at the laboratory, the participants were seated with an experimenter in a small room in front of a computer. They were first told their responses were completely anonymous because the ID numbers were used to manage the data. They were then given brief instructions for completing the experiment. After this, the experimenter left of the room to ensure the participants' anonymity. All tasks were carried out using a computer program written inPsychoPy. During the tasks, the desktop background featured the eye-like images (Haley and Fessler, 2005). In the beginning, however, the program window covered the desktop screen so participants were not able to view the eye-like images (Fig. 1A).

When they were left alone, the participants entered their identification numbers into a pop-up window. Then, they performed two filler tasks on the computer: the Multidimensional Perfectionism Cognition Inventory (Kobori and Tanno, 2004) and the Alternative Uses Task (provide alternative uses of pencil and of clothespins; see Vohs, Redden, and Rahinel, 2013). These tasks were conducted to acclimatize the participants to the experimental environment and were not related to the main task.

After they completed the filler tasks, the participants were asked to donate less than half of their participation fee to the Japanese Red Cross Society (0-500 JPY; in units of $10 \mathrm{JPY}$ ). At that time, they saw an amount of money that ostensibly represented the mean donation of the previous eight participants. In the prosocial norm condition, the participants were informed that the previous eight participants donated 438 JPY on average. In the non-prosocial norm condition, the participants were informed that they donated only 38 JPY. At the same time, the size of the program window was altered to manipulate the eyes. In the eyes condition, the size of the program window was altered to reveal the eye-like images (Fig. 1B), whereas in the no eyes condition the size of the program window changed but the eye-like images were not visible (Fig. 1C). 
The participants first entered their donation amount in the pop-up window. Next, they took a brown envelope containing their participation fee from a drawer, and then they put their donation into the white envelope. The participation fee consisted of five 10yen coins, one 50-yen coin, four 100-yen coins and one 500-yen coin. After they finished the donation task, participants responded to questions concerning how much they thought the other participants had donated on average ( 0 to $500 \mathrm{JPY}$; in units of $50 \mathrm{JPY}$ ), their perception of anonymity $(1=$ not at all, $7=$ very much), and any potential inferences regarding the purpose of the experiment. They then called the experimenter and let him know they were finished with the tasks. After the debriefing, they answered some questions, including a question about their beliefs concerning the reality of the normative cues.

\subsection{Results}

Six of the 139 participants entered different donation amounts on the PC than they donated in the real-world laboratory setting. Data from these participants were excluded from the following analyses.

The norm manipulation was successful; the participants in the prosocial norm condition thought that the other participants donated more than did those in the nonprosocial norm condition $\left(M_{\text {prosocial }}=302.90, S D_{\text {prosocial }}=103.57, M_{\text {non-prosocial }}=55.47\right.$, $\left.S D_{\text {non-prosocial }}=29.70 ; t(79.92)=19.02, p<.001, d=3.20\right)$. After the debriefing, 35 participants mentioned their doubts concerning the reality of the norm manipulation. However, because we asked them questions concerning their beliefs in the reality of the norm information when we had already explained that the donation amounts of others were not real, this explanation could have affected their answers. Then, we focused on the perceptions of the donations of others, which we asked about before the debriefing. We found that, even among these participants, the perceptions of the donations of others were higher in the prosocial than the non-prosocial norm condition $\left(M_{\text {prosocial }}=269.64\right.$, $\left.S D_{\text {prosocial }}=117.33 ; M_{\text {non-prosocial }}=28.57, S D_{\text {non-prosocial }}=26.73\right)$. Therefore, the results of these participants were included in the later analyses (even if we were to exclude these participants, we would have found the same main results). As for the anonymity rating, there was no significant effect of eye condition $\left(M_{\text {eyes }}=5.79, S D_{\text {eyes }}=1.68, M_{\text {noeyes }}=5.88\right.$, $\left.S D_{\text {noeyes }}=1.21 ; t(118.25)=0.36, p=.716, d=0.06\right)$.

Across conditions, 76 of the 133 participants donated something. The mean 
donation amount was 108.50 JPY ( $S D=158.22)$ out of 500 JPY. Fig. 2 shows the boxplot of the donation amount for each condition.

Since the donation distribution was crowded with units of 100 JPY, we divided the donation amount into six categories (0: 0 JPY, 1: 1-100 JPY, 2: 101-200 JPY, 3: 201-300 JPY, 4: 301-400 JPY, 5: 401-500 JPY). In further analysis, we used this categorical variable as the indicator of the donation amount. We conducted proportional odds ordinal logistic regression analyses for the donation amount (Table 1). In Model 1, we put control (dummy variable of sex) and predictor (dummy variables of eyes and norms) variables into the regression. As shown in Table 1, we found a significant effect of norm condition and a marginally non-significant effect of eye condition. There was no significant effect of sex. We added the interaction term between eyes and norms in Model 2 and found that this interaction effect was significant. To investigate the effects of eyes per norm condition, we conducted simple slope analyses. The results of these analyses showed that when there was a non-prosocial norm, the effect of eyes on donation was not significant $(b=-0.05, O R=0.95, p=.917)$. On the other hand, when there was a prosocial norm, the effect of eyes was significantly positive $(b=1.23, O R=$ $3.42, p=.006)$.

We also conducted an ordinal logistic regression analysis utilizing perception of the donations of others as an independent variable (11 points scale; $1=0 \mathrm{JPY}, 11=500$ JPY), instead of the dummy variable of the norm condition. Again, we found a significant interaction effect $(b=0.26, O R=1.30, p=.024)$ between eyes and norms such that when individuals thought others donated relatively less, the effect of the watching eyes on their donations was not significant $(b=-0.22, O R=0.80, p=.650)$. On the other hand, when they thought others donated relatively more, this effect was significantly positive $(b=$ $1.29, O R=3.65, p=.005)$.

Next, we conducted a logistic regression analysis for the dependent variable that reflected whether something (1) or nothing (0) was donated. The independent variable was the same as in the previous ordinal logistic model. As a result, there were no significant main effects of $\operatorname{sex}(b=0.30, O R=1.35, p=.403)$, eyes $(b=0.40, O R=1.50$, $p=0.255)$, or norms $(b=-0.06, O R=0.94, p=0.870)$. However, the interaction between eyes and norms was marginally non-significant ( $b=1.26, O R=3.54, p=.078)$. A simple slope analysis showed that when there was a non-prosocial norm, the effect of eyes on donation was not significant $(b=-0.25, O R=0.78, p=.628)$. On the other hand, when 
there was a prosocial norm, the effect of eyes was significantly positive $(b=1.02, O R=$ $2.76, p=.043)$. These results were replicated when we used the perception of norm as an independent variable, instead of norm condition. The interaction between eyes and norms was marginally non-significant $(b=0.22, O R=1.25, p=.086)$. A simple slope analysis showed that when there was a non-prosocial norm, the effect of watching eyes on donations was not significant $(b=-0.23, O R=0.79, p=.641)$. On the other hand, when there was a prosocial norm, this effect was marginally non-significant $(b=1.08, O R=$ $2.95, p=.054)$.

\subsection{Discussion}

To investigate the mechanism involved in the watching eyes effect, the present study investigated whether it is influenced by prosocial norms. The results showed that the watching eyes promoted donations only when others behaved generously; that is, when a prosocial norm existed. In line with some previous arguments (e.g., Nettle et al., 2013), these results support the avoiding a bad reputation hypothesis. When a prosocial norm exists, not behaving generously leads to a bad reputation as a norm violator. To avoid such a risk, when participants are "watched" by the eye-like images, they conform to the prosocial norm. On the other hand, when there is a non-prosocial norm, it is unlikely that a non-prosocial person will be punished by an observer. In this case, it is already understood that eyes will have no effect on prosocial behaviors.

Two previous studies also investigated the watching eyes effect by manipulating norm information (Bateson et al., 2013; Fathi et al., 2014). In particular, Fathi et al. (2014) conducted a donation experiment in a laboratory as was the case with our study. However, their results did not support the avoiding a bad reputation hypothesis. One difference between ours and Fathi et al.'s (2014) study is the strength of the norm manipulation. Fathi et al. (2014) manipulated norms by changing the types of dominant coins in the charity donation jar. In contrast, we explicitly showed an average donation amount received from the previous eight participants. We considered this to function as a clear normative point. In fact, unlike Fathi et al. (2014), we were able to test the effectiveness of our norm manipulation, and found that the manipulation was successful. It was easy for the participants to recognize what the normative behaviors and norm violations were. Therefore, the participants could expect a bad reputation for non-normative behavior performed in front of the eye-like images.

Some studies have suggested that the watching eyes effect is mediated by the 
concern for obtaining a good reputation, rather than the concern for avoiding a bad reputation (e.g., Oda et al., 2011; Powell et al., 2012). Particularly, Oda et al. (2011) demonstrated that eyes activated the expectation of a future reward. This, in turn, promoted monetary distributions to others. To consider the apparent contradiction between the results of Oda et al.'s (2011) study and ours, we focus on the differences in the experimental settings of these studies. Unlike the previous study, we showed norm information to participants in both the prosocial and non-prosocial norm conditions. This norm information may have activated the concern for avoiding a bad reputation as a norm violator. This, in turn, may have led to promotion of prosocial behavior only in the presence of a prosocial norm. On the other hand, as Oda et al. (2011) demonstrated, if normative cues do not exist, the concern for obtaining a good reputation may promote prosocial behavior in front of watching eyes.

Although some previous studies have suggested that eyes increase the numbers of donations obtained (e. g., Nettle et al., 2013), we found relatively weak results when we investigated whether the eyes and norms affected the dependent variable that reflected whether something or nothing was donated. We believe this was due to our manipulation of norms. In line with Nook et al. (2016), we showed average donation amounts in relation to social norms. Unlike the donor ratio (e.g., Frey and Meier, 2004), the average donation amount tells how much people donated on average, but it cannot tell how many people actually donated. In particular, the 38 JPY that we portrayed as the average donation from the previous eight participants in the non-prosocial norm condition could be interpreted as representing how many people donated nothing, with most of the contributions coming through the high donation amounts of a few, or how many people donated small amounts of money. Thus, in our experiment, we demonstrated how watching eyes affected the decision of how much, rather than whether, to donate.

In the original study, we found clear results that support our hypothesis. On the other hand, some studies did not find that the watching eyes effect occurs only when a prosocial norm exists (Bateson et al., 2013; Fathi et al., 2014). Given that the results of previous studies are mixed, it will be premature to draw a conclusion from a single experiment. Hence, we conducted a replication study.

Before conducting the experiment, we pre-registered the procedure and our hypothesis on the Open Science Framework. To generalize the results, we changed the environment, dependent variable, and participants in the replication study. However, we 
retained the main manipulation of the original study; we manipulated the norms and eyes in the same way as in the original study. We investigated whether watching eyes promoted generosity only when prosocial norms existed.

\section{Replication Study}

In the next study, we tried to replicate the original study. We pre-registered the nature of the effect, the study design, the differences between the original and the replication study, and the analysis plan on the Open Science Framework (OSF). The registration is available on the OSF site (https://osf.io/wknd6/).

The replication study differed from the original study in three points. First, although we conducted the original study in a lab, we conducted the replication study online. Considering that some previous studies involved web-based experiments about the watching eyes effect (e.g., Komiya et al., 2016; Pfattheicher and Keller, 2015), an online experiment is not inappropriate for this setting. Second, the participants' ages were between 20 and 60 . Third, instead of donating money, participants volunteered their effort for charity. We referred to previous studies that used effortful tasks to estimate generosity (Ariely, Bracha, and Meier, 2009; Coleman and Williams, 2013; Imas, 2014).

\subsection{Methods}

\subsubsection{Participants and design}

Four hundred Japanese crowdsourcing workers aged 20-60 years $(M=38.5, S D$ $=9.40 ; 182$ males and 218 females), recruited from Crowdworks (a crowdsourcing service in Japan), were paid 300 JPY to participate. They were randomly allocated to one condition of a 2 (eyes: eyes vs. no eyes) $\times 2$ (norm: prosocial vs. non-prosocial) betweenparticipants design: (a) prosocial norm with eyes $(n=100)$, (b) prosocial norm without eyes $(n=100)$, (c) non-prosocial norm with eyes $(n=99)$, and $(d)$ non-prosocial norm without eyes $(n=101)$. The participant sex ratio was almost equal throughout all conditions. The sample size was decided following the guidelines of Simonsohn (2015); Simonsohn (2015) suggested that the sample size of a replication study should be at least 2.5 times the size of the original sample. This study was approved by the ethics committee at the Graduate School of Education of Kyoto University, and consent was obtained from all participants before the experiment was conducted.

\subsubsection{Procedure}

The survey page was made by Qualtrics online survey software 
(http://www.qualtrics.com/). The survey can be answered only by PC. The background of the page featured the eye-like images that were the same as in the original study. The question area covered the eyes in the beginning so participants could not see the images. To control the experimental settings, only participants who reported that they were in a room alone could answer the questionnaire. Additionally, we asked participants to maximize the survey page before starting the survey.

Before working for charity, participants worked for themselves. Participants worked on a task that required typing a handwritten string of 8 digits from 1 to 8 randomly in a line (e.g., 14,265,873). There was a total of 25 strings. They were explained that a fee of 100JPY (out of a total fee of $300 \mathrm{JPY}$ for the whole experiment) was the reward for this task. That is, they would get 4 JPY per string entered. All of them entered the 25 strings. This effortful task for themselves was conducted to link the task contents and reward.

Then, participants were asked to do the same effortful task. They were informed that in the next task, they could not obtain their own reward but in return they could donate money to the Japanese Red Cross Society. They were also informed that they could decide how many numbers they would enter by themselves (0-50 strings; 4JPY donated to Japanese Red Cross Society per string).

As in the original study, participants saw an amount of work that ostensibly represented the mean quantity of the previous eight participants' work (43 strings: prosocial norm or 3 strings: non-prosocial norm). At the same time, the eyes were manipulated. Only in the eyes condition, the question area became translucent to reveal the eye-like images (Fig 3A; larger images are uploaded on https://osf.io/pvksd/). In the no eyes condition, the question area covered the eyes (Fig 3B).

They first entered their amount of work on the PC using the slider. Then, they actually performed the effortful task for charity. After they finished the effortful task, participants responded to questions concerning how much they thought the other participants had donated on average ( 0 to 50 strings; in units of 5 strings) and were tested on their knowledge about how much money would be donated to charity if they entered one string (1: 4 JPY, 2: $400 \mathrm{JPY}, 3: 800 \mathrm{JPY}$ ). Additionally, they answered some questions about the environment such as how wide their room was, the presence of a poster with a human face in front of them, how many people were in their room during their answers. 
Lastly, they were debriefed.

\subsection{Results}

Nine of the 400 participants answered a manipulation check question incorrectly; they did not recognize how much money would be donated to charity correctly. Data from these participants were excluded from the following analyses.

The norm manipulation was successful; participants in the prosocial norm condition thought that the other participants donated more than did those in the nonprosocial norm condition $\left(M_{\text {prosocial }}=34.09, S D_{\text {prosocial }}=11.39, M_{\text {non-prosocial }}=12.76, S D_{\text {non- }}\right.$ prosocial $=10.62 ; t(387.82)=19.16, p<.001, d=1.94)$.

Across conditions, 380 of the 391 participants worked for charity at least once. Because almost all participants worked for charity at least once, we did not conduct a logistic regression analysis for the dependent variable that reflected whether something (1) or nothing (0) was donated. The mean amount was 26.87 times $(S D=18.71)$ out of 50 times. Fig. 4 shows the boxplot of the work amount for each condition.

As in the original study, we divided the work amount into six categories (0: 0 , 1: 1-10, 2: 11-20, 3: 21-30, 4: 31-40, 5: 41-50). On further analysis, we used this categorical variable as the indicator of the work amount. We conducted proportional odds ordinal logistic regression analyses for the amount (Table 2). As shown in Table 2, we found a significant effect of norm condition. However, we did not find a significant main effect of eyes or an interaction effect. The results of simple slope analyses showed that the effect of eyes was not significant regardless of norm condition (prosocial norm: $b=0.05, O R=1.05, p=0.853$; non-prosocial norm: $b=-0.04, O R=0.96, p=0.867$ ).

We next conducted an ordinal logistic regression analysis utilizing perception of the donations of others as an independent variable, instead of the dummy variable of the norm condition. Again, we did not find a significant interaction effect $(b=0.07, O R=$ $1.08, p=.324$ ) between eyes and norms. The coefficient of eyes did not change whether participants perceived a relatively prosocial norm $(b=0.39, O R=1.48, p=.232)$ or a non-prosocial norm $(b=-0.06, O R=0.94, p=.844)$.

To investigate why the replication study did not replicate the original, we also conducted further analyses. Because we did not register these analyses in advance, we 
should be careful in interpreting the statistical significance tests. Nonetheless, we consider that exploratory analyses are informative for future research.

One possible reason is that we could not control the levels of anonymity in the online experiment. We excluded participants who reported that there were pictures or posters that have faces or that there were people around them during their answer $(n=$ 28). We conducted ordinal logistic analysis the same as in the above analyses. When we used the dummy variable of the norm condition, the interaction effect of eyes and norms was $b=0.14(O R=1.15, p=.731)$. When we used perception of the donations of others, the interaction effect of eyes and norms was $b=0.09(O R=1.10, p=.231)$.

\subsection{Discussion}

In the replication study, we tried to replicate the original study. Although we manipulated eyes and norms in accordance with the original study, the results of the replication study were not consistent with the original results; the eyes did not promote generosity regardless of whether a prosocial norm existed or not.

To generalize the results, we modified the dependent variable from the original study; participants conducted an effortful task for charity, instead of donating money directly. This may have caused the difference in the results. As figs 2 and 4 show, the distribution of the replication study was different from that of the original study. In the replication study, the full distribution increased and almost all people made an effort for charity at least once regardless of conditions. More importantly, in the replication study, it seems more appropriate to say that participants followed the norm where there were no eyes, rather than violating the norm under the eyes. We compared the simple slopes of the norm on the dependent variable (donation or work amount) per eyes conditions. In the eyes condition, the effect of the norm condition on the dependent variable was not different between the original study $(b=1.33, O R=3.80, p=.004)$ and the replication study $(b=1.46, O R=4.30, p<.001)$. On the other hand, in the no eyes condition, the effect of norm was only significant in the replication study (original study: $b=0.05, O R$ $=1.06, p=.905$; replication study: $b=1.36, O R=3.91, p<.001)$. That is, in the replication study, participants followed the prosocial norm regardless of the presence of watching eyes. One explanation of this difference is that the incentive to deviate from the prosocial norm was smaller in the replication study than in the original study. While people who violated the prosocial norm could keep their money in the original study, violators only saved their effort in the replication study. If the benefits from deviating 
from the prosocial norm are small, people may be likely to comply with prosocial norms regardless of the presence of watching eyes. Hence, in the replication study, people are likely to follow the norm even when there are no eyes.

We also modified the location of the experiment; while the original study was conducted in a laboratory, the replication study was online. This could also have influenced the results. Previous studies suggested that the number of people in an area can moderate the watching eyes effect (e.g., Bateson et al., 2013; Ernest-Jones et al., 2011). Although we have controlled the influence of people or pictures around participants, we could have failed to control other confounding factors that affect the level of anonymity.

Anyway, we did not replicate the results of the original study. In the general discussion, we comprehensively interpret and discuss the results of the original and replication studies.

\section{General Discussion}

Although many researchers have studied the watching eyes effect, the existence of the effect is still being discussed. Some findings have found watching eyes promotes generosity (e.g., Haley and Fessler, 2005; Oda et al., 2011), while others have not found such results (e.g., Matsugasaki et al., 2015; Raihani and Bshary, 2012; Tane and Takezawa, 2011). A recent meta-analysis showed that the watching eyes effect did not occur when moderation factors were not considered (Northover et al., 2017). To investigate when and why the watching eyes promote generosity, we manipulated both the presence of eyes and the social norm.

Across two studies, we investigated whether the eyes effect occurred only when a prosocial norm was present. In the original study, we found that eyes promote generosity only when a prosocial norm was present. These results support the avoiding a bad reputation hypothesis. On the other hand, in the replication study, we found that eyes did not promote generosity regardless of the norm.

How should we interpret the contradiction in these results? One possible interpretation is that the results of the original study were a false positive. Not only the results of our replication study, but the results of other studies that investigated the moderation effect of norms were also different from our original study (Bateson et al., 
2013; Fathi et al., 2014). Further, recently, Oda and Ichihashi (2016) also investigated whether the watching eyes effect differs depending on norms and they reported different conclusions about the moderation effect of norms from our original study. Considering the existence of these studies, we cannot deny the possibility that the significant results of the original study were found by chance.

The other possibility is that there are other moderators, such as the incentive of norm-violation. As discussed above, if the incentive of norm-violation is low, people may be likely to follow norm even when the eyes are not shown. Additionally, we do not think that we can explain all of the previous studies that did not find a watching eyes effect moderated by the effect of norms. There could be other moderators, such as the number of people in an area (c.f., Ernest-Jones et al., 2011). In future studies, we should consider the existence of further moderation factors.

To investigate whether the watching eyes effect depends on social norms in the future, it is also necessary to consider cultural differences. Gelfand et al. (2011) suggested that there is cultural variation in the strength of social norms. As Table 1 of Gelfand et al. (2011) shows, Japan has relatively strong norms and low tolerance of deviant behavior. Therefore, it is possible to believe Japanese participants were sensitive to the norm information. We do not think that cultural differences can explain the contradiction of our studies because the two studies were conducted in the same culture. However, future studies are needed to investigate whether the watching eyes effect is moderated by norms in other cultures.

Since we did not replicate the results of the first study, it is difficult to draw conclusions about the mechanism of the eyes effect and the influence of norms. The moderation effect of norms can occur, but it does not always. Recently, the watching eyes effect has been drawing attention and some researchers have focused on whether the watching eyes promotes generosity only when a prosocial norm exists (Bateson et al., 2013; Fathi et al., 2014; Oda and Ichihashi, 2016). Since this is now actively discussed by many researchers, we consider that null results are as important as positive ones. Although we did not replicate the results of our first study, we conducted the replication study after registering the hypothesis and methods. In the future, it is necessary to draw conclusions after accumulating knowledge from many researchers.

Acknowledgements 
We thank Dr. Kevin Haley and Dr. Daniel Fessler for permission to use the eye-like images. We would also like to thank Dr. Asuka Komiya and Dr. Yuji Ogihara for their helpful comments on earlier versions of this manuscript.

Data Availability:

The data associated with this research are available at [https://osf.io/5dp7s/].

Funding:

This work was supported by the Kyoto University Design School and Grant-in-Aid for JSPS Research Fellow [16J11139]. 


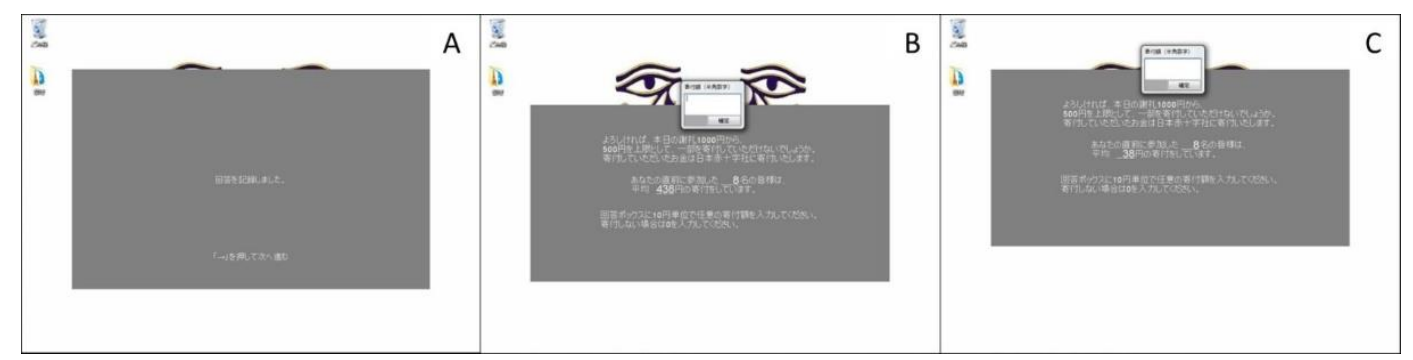

Fig. 1. Participant view of the original study. Fig 1A represents the screen before the donation phase. Fig 1B represents the screen in the eyes condition during the donation phase. Fig $1 \mathrm{C}$ represents the screen in the no eyes condition during the donation phase. 


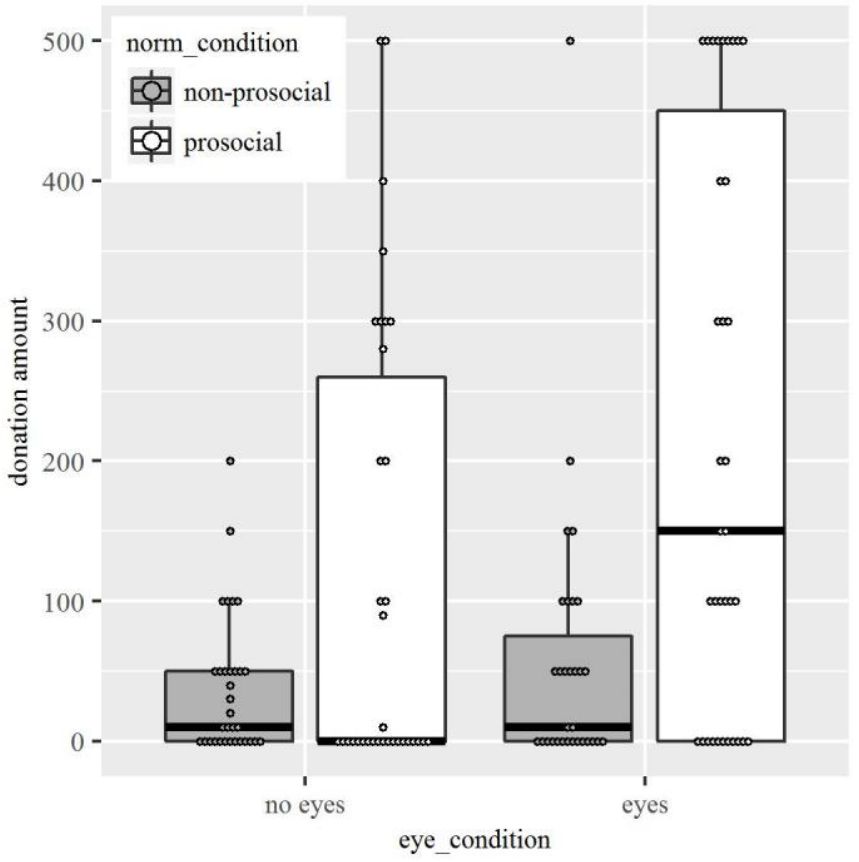

Fig. 2: Boxplot of the donation amount for each condition in the original study. Each dot represents one observation. 


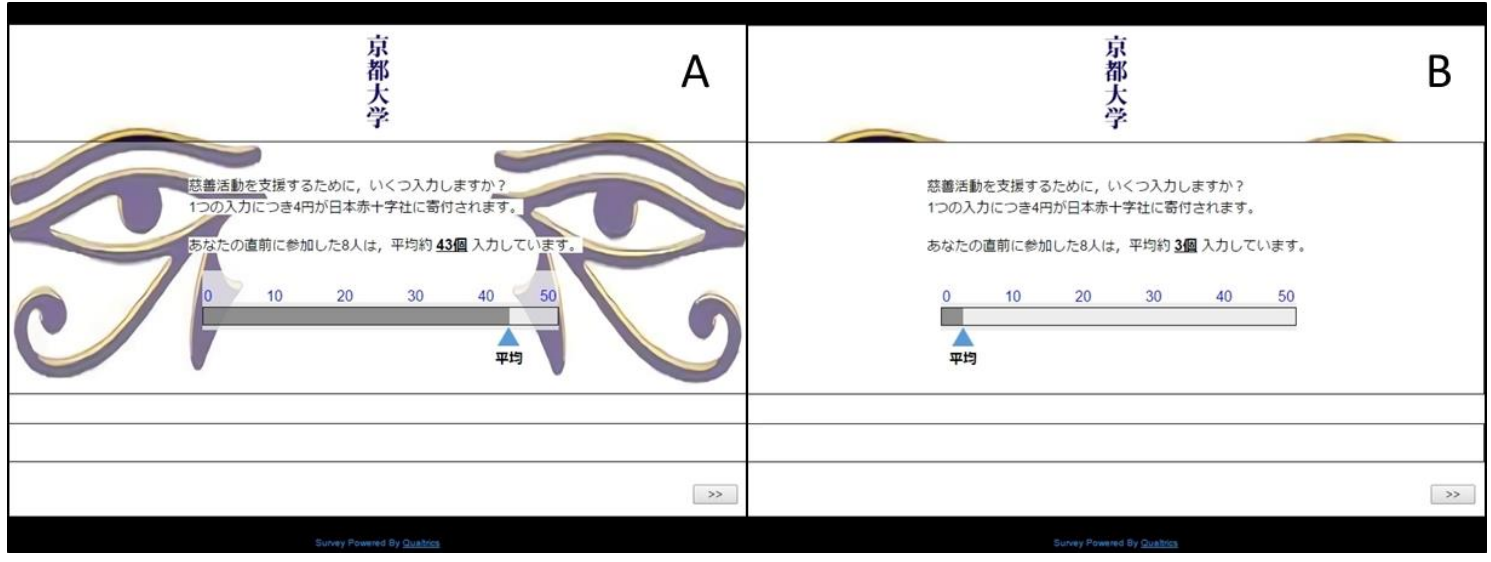

Fig. 3. Participant view of the replication study. Fig 3A represents the screen in the eyes condition during the donation phase. Fig 3B represents the screen in the no eyes condition during the donation phase. 


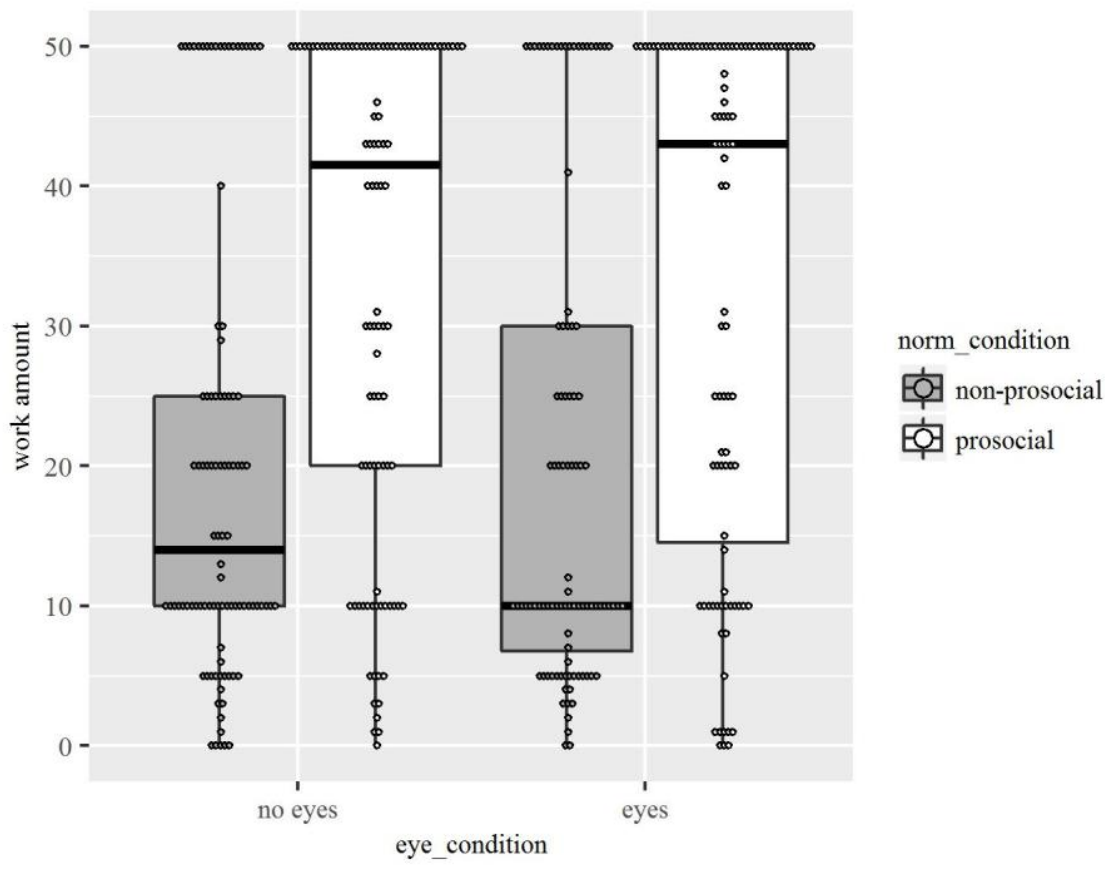

Fig. 4: Boxplot of the work amount for each condition in the replication study. Each dot represents one observation. 
1 Table 1. Ordinal Logistic Regression Analysis Predicting Donation Amounts ( $=133)$ : Original Study

\begin{tabular}{|c|c|c|c|c|c|c|c|c|c|c|}
\hline & Model 1 & & & & & Model 2 & & & & \\
\hline & Estimate & $O R^{\mathrm{a}}$ & $95 \% \mathrm{CI}$ & $S E$ & $p$ & Estimate & $O R^{\mathrm{a}}$ & $95 \% \mathrm{CI}$ & $S E$ & $p$ \\
\hline Intercept: $1(Y>=2)$ & 0.36 & & & 0.18 & 0.044 & 0.36 & & & 0.18 & 0.045 \\
\hline Intercept: $2(Y>=3)$ & -1.01 & & & 0.20 & $<.001$ & -1.04 & & & 0.20 & $<.001$ \\
\hline Intercept: $3(Y>=4)$ & -1.54 & & & 0.23 & $<.001$ & -1.58 & & & 0.23 & $<.001$ \\
\hline Intercept: $4(Y>=5)$ & -2.05 & & & 0.27 & $<.001$ & -2.10 & & & 0.27 & $<.001$ \\
\hline Intercept: $5(Y>=6)$ & -2.38 & & & 0.31 & $<.001$ & -2.44 & & & 0.31 & $<.001$ \\
\hline $\operatorname{Sex}(M:-0.43, F: 0.57)^{b}$ & 0.28 & 1.32 & {$[0.70,2.50]$} & 0.32 & 0.385 & 0.28 & 1.32 & {$[0.70,2.49]$} & 0.32 & 0.391 \\
\hline Eyes (No eyes: -0.50 , Eyes: 0.50 ) & 0.54 & 1.72 & {$[0.91,3.23]$} & 0.32 & 0.093 & 0.61 & 1.85 & {$[0.98,3.50]$} & 0.33 & 0.059 \\
\hline Norm (non-prosocial: -0.52 , prosocial: 0.48 ) & 0.68 & 1.98 & {$[1.05,3.74]$} & 0.32 & 0.035 & 0.69 & 1.99 & {$[1.05,3.78]$} & 0.33 & 0.035 \\
\hline Eyes $\times$ Norm & & & & & & 1.28 & 3.60 & {$[1.00,12.89]$} & 0.65 & 0.049 \\
\hline Residual deviance & 370.39 & & & & & 366.49 & & & & \\
\hline Nagelkerke_R ${ }^{2}$ & 0.06 & & & & & 0.09 & & & & \\
\hline AIC & 386.39 & & & & & 384.49 & & & & \\
\hline
\end{tabular}

2 a odds ratio

$3 \quad$ b Every dummy variable was centered 
5 Table 2. Ordinal Logistic Regression Analysis Predicting Work Amount $(\mathrm{N}=391)$ : Replication Study

\begin{tabular}{|c|c|c|c|c|c|c|c|c|c|c|}
\hline & Model 1 & & & & & Model 2 & & & & \\
\hline & Estimate & $O R^{\mathrm{a}}$ & $95 \% \mathrm{CI}$ & $S E$ & $p$ & Estimate & $O R^{\mathrm{a}}$ & $95 \% \mathrm{CI}$ & $S E$ & $p$ \\
\hline Intercept: $1(Y>=2)$ & 3.85 & & & 0.31 & $<.001$ & 3.85 & & & 0.31 & $<.001$ \\
\hline Intercept: $2(Y>=3)$ & 0.62 & & & 0.11 & $<.001$ & 0.62 & & & 0.11 & $<.001$ \\
\hline Intercept: $3(Y>=4)$ & 0.04 & & & 0.11 & .736 & 0.04 & & & 0.11 & .737 \\
\hline Intercept: $4(Y>=5)$ & -0.49 & & & 0.11 & $<.001$ & -0.49 & & & 0.11 & $<.001$ \\
\hline Intercept: $5(Y>=6)$ & -0.63 & & & 0.11 & $<.001$ & -0.63 & & & 0.11 & $<.001$ \\
\hline $\operatorname{Sex}(M:-0.54, F: 0.46)^{b}$ & 0.65 & 1.92 & {$[1.31,2.80]$} & 0.19 & $<.001$ & 0.65 & 1.91 & {$[1.31,2.80]$} & 0.19 & $<.001$ \\
\hline Age & 0.03 & 1.03 & {$[1.01,1.06]$} & 0.01 & 0.001 & 0.03 & 1.03 & {$[1.01,1.06]$} & 0.01 & 0.001 \\
\hline Eyes (No eyes: -0.50 , Eyes: 0.50 ) & 0.00 & 1.00 & {$[0.69,1.45]$} & 0.19 & 0.996 & 0.00 & 1.00 & {$[0.69,1.46]$} & 0.19 & 0.987 \\
\hline Norm (non-prosocial: -0.50 , prosocial: 0.50 ) & 1.41 & 4.10 & {$[2.79,6.02]$} & 0.20 & $<.001$ & 1.41 & 4.10 & {$[2.79,6.03]$} & 0.20 & $<.001$ \\
\hline Eyes $\times$ Norm & & & & & & 0.10 & 1.10 & {$[0.52,2.32]$} & 0.38 & 0.803 \\
\hline Residual deviance & 1052.99 & & & & & 1052.93 & & & & \\
\hline Nagelkerke_R ${ }^{2}$ & 0.17 & & & & & 0.17 & & & & \\
\hline AIC & 1070.99 & & & & & 1072.93 & & & & \\
\hline
\end{tabular}

$6{ }^{a}$ odds ratio

$7 \quad{ }^{\mathrm{b}}$ Every dummy variable was centered 


\section{Reference}

Ariely, D., Bracha, A., \& Meier, S. (2009). Doing Good or Doing Well? Image Motivation and Monetary Incentives in Behaving Prosocially. American Economic Review, 99(1), 544555. doi:10.1257/aer.99.1.544

Barclay, P., \& Willer, R. (2007). Partner choice creates competitive altruism in humans. Proceedings of the Royal Society B: Biological Sciences, 274(1610), 749-753. doi:10.1098/rspb.2006.0209

Bateson, M., Callow, L., Holmes, J. R., Redmond Roche, M. L., \& Nettle, D. (2013). Do images of 'watching eyes' induce behaviour that is more pro-social or more normative? A field experiment on littering. PLoS One, 8(12), e82055. doi:10.1371/journal.pone.0082055

Bateson, M., Nettle, D., \& Roberts, G. (2006). Cues of being watched enhance cooperation in a real-world setting. Biology Letters, 2(3), 412-414. doi:10.1098/rsbl.2006.0509

Chudek, M., \& Henrich, J. (2011). Culture-gene coevolution, norm-psychology and the emergence of human prosociality. Trends in Cognitive Sciences, 15(5), 218-226. doi:10.1016/j.tics.2011.03.003

Coleman, N. V., \& Williams, P. (2013). Feeling Like My Self: Emotion Profiles and Social Identity. Journal of Consumer Research, 4O(2), 203-222. doi:10.1086/669483

Ernest-Jones, M., Nettle, D., \& Bateson, M. (2011). Effects of eye images on everyday cooperative behavior: a field experiment. Evolution and Human Behavior, 32(3), 172178. doi:10.1016/j.evolhumbehav.2010.10.006

Fathi, M., Bateson, M., \& Nettle, D. (2014). Effects of watching eyes and norm cues on charitable giving in a surreptitious behavioral experiment. Evolutionary $P_{\text {sychology, }}$ 12(5), 878-887. doi:10.1177/147470491401200502

Frey, B. S., \& Meier, S. (2004). Social comparisons and pro-social behavior : Testing "conditional cooperation" in a field experiment. The American Economic Review, 94(5), 1717-1722. doi:10.1257/0002828043052187

Gelfand, M. J., Raver, J. L., Nishii, L., Leslie, L. M., Lun, J., Lim, B. C., . . Yamaguchi, S. (2011). Differences Between Tight and Loose Cultures: A 33-Nation Study. Science, 332(6033), 1100-1104. doi:10.1126/science.1197754

Haley, K. J., \& Fessler, D. M. T. (2005). Nobody's watching? Evolution and Human Behavior, 26(3), 245-256. doi:10.1016/j.evolhumbehav.2005.01.002

Ikeuchi, H. (2010). Animistic thinking in adults: The memorial service for dolls as a voluntary loss. Japanese journal of social psychology, 25(3), 167-177.

Imas, A. (2014). Working for the "warm glow": On the benefits and limits of prosocial incentives. Journal of Public Economics, 114, 14-18. doi:10.1016/j.jpubeco.2013.11.006 
Kanai, Y., Sasagawa, S., Chen, J., Sizuki, S., Shimada, H., \& Sakano, Y. (2004). Development and Validation of the Japanese Version of Social Phobia Scale and Social Interaction Anxiety Scale. Japanese Journal of Psychosomatic Medicine, 44(11), 841-850.

Kobori, O., \& Tanno, Y. (2004). Development of Multidimensional Perfectionism Cognition Inventory. Japanese Journal of Personality, 13(1), 34-43. doi:10.2132/personality.13.34

Kojima, Y., Ohta, K., \& Sugawara, K. (2003). Praise seeking and rejection avoidance needs scales: Development and examination of validity. The Japanese Journal of Personality, 11(2), 86-98.

Komiya, A., Oishi, S., \& Lee, M. (2016). The Rural-Urban Difference in Interpersonal Regret. Personality and Social Psychology Bulletin, 42(4), 513-525. doi:10.1177/0146167216636623

Masclet, D., Noussair, C., Tucker, S., \& Villeval, M. C. (2003). Monetary and nonmonetary punishment in the voluntary contributions mechanism. American Economic Review, 93(1), 366-380. doi:10.1257/000282803321455359

Matsugasaki, K., Tsukamoto, W., \& Ohtsubo, Y. (2015). Two Failed Replications of the Watching Eyes Effect. Letters on Evolutionary Behavioral Science, 6(2). doi:10.5178/lebs.2015.36

Nettle, D., Harper, Z., Kidson, A., Stone, R., Penton-Voak, I. S., \& Bateson, M. (2013). The watching eyes effect in the Dictator Game: it's not how much you give, it's being seen to give something. Evolution and Human Behavior, 34(1), 35-40. doi:10.1016/j.evolhumbehav.2012.08.004

Nook, E. C., Ong, D. C., Morelli, S. A., Mitchell, J. P., \& Zaki, J. (2016). Prosocial Conformity: Prosocial Norms Generalize Across Behavior and Empathy. Personality and Social Psychology Bulletin, 42(8), 1045-1062. doi:10.1177/0146167216649932

Northover, S. B., Pedersen, W. C., Cohen, A. B., \& Andrews, P. W. (2017). Artificial surveillance cues do not increase generosity: two meta-analyses. Evolution and Human Behavior, 38(1), 144-153. doi:10.1016/j.evolhumbehav.2016.07.001

Oda, R., \& Ichihashi, R. (2016). Effects of Eye Images and Norm Cues on Charitable Donation: A Field Experiment in an Izakaya. Evolutionary Psychology, 14(4). doi:10.1177/1474704916668874

Oda, R., Kato, Y., \& Hiraishi, K. (2015). The Watching-Eye Effect on Prosocial Lying. Evolutionary Psychology, 13(3). doi:10.1177/1474704915594959

Oda, R., Niwa, Y., Honma, A., \& Hiraishi, K. (2011). An eye-like painting enhances the expectation of a good reputation. Evolution and Human Behavior, 32(3), 166-171. doi:10.1016/j.evolhumbehav.2010.11.002 
80

Oshio, A., Abe, S., \& Cutrone, P. (2012). Development, Reliability, and Validity of the Japanese Version of Ten Item Personality Inventory (TIPI-J). Japanese Journal of Personality, 21(1), 40-52. doi:10.2132/personality.21.40

Pfattheicher, S., \& Keller, J. (2015). The watching eyes phenomenon: The role of a sense of being seen and public self-awareness. European Journal of Social Psychology, 45(5), 560-566. doi:10.1002/ejsp.2122

Powell, K. L., Roberts, G., \& Nettle, D. (2012). Eye Images Increase Charitable Donations: Evidence From an Opportunistic Field Experiment in a Supermarket. Ethology, 118(11), 1096-1101. doi:10.1111/eth.12011

Raihani, N. J., \& Bshary, R. (2012). A positive effect of flowers rather than eye images in a large-scale, cross-cultural dictator game. Proc Biol Sci, 279(1742), 3556-3564. doi:10.1098/rspb.2012.0758

Rigdon, M., Ishii, K., Watabe, M., \& Kitayama, S. (2009). Minimal social cues in the dictator game. Journal of Economic Psychology, 30(3), 358-367. doi:10.1016/j.joep.2009.02.002

Shang, J., \& Croson, R. (2009). A Field Experiment in Charitable Contribution: The Impact of Social Information on the Voluntary Provision of Public Goods. Economic Journal, 119(540), 1422-1439. doi:10.1111/j.1468-0297.2009.02267.x

Simonsohn, U. (2015). Small telescopes: detectability and the evaluation of replication results. Psychol Sci, 26(5), 559-569. doi:10.1177/0956797614567341

Sparks, A., \& Barclay, P. (2013). Eye images increase generosity, but not for long: the limited effect of a false cue. Evolution and Human Behavior, 34(5), 317-322. doi:10.1016/j.evolhumbehav.2013.05.001

Sylwester, K., \& Roberts, G. (2013). Reputation-based partner choice is an effective alternative to indirect reciprocity in solving social dilemmas. Evolution and Human Behavior, 34(3), 201-206. doi:10.1016/j.evolhumbehav.2012.11.009

Tane, K., \& Takezawa, M. (2011). Perception of human face does not induce cooperation in darkness. Letters on Evolutionary Behavioral Science, 2(2). doi:10.5178/lebs.2011.15

Vohs, K. D., Redden, J. P., \& Rahinel, R. (2013). Physical order produces healthy choices, generosity, and conventionality, whereas disorder produces creativity. Psychological Science, 24(9), 1860-1867. doi:10.1177/0956797613480186 